\title{
Doctors died of Suspected COVID-19
}

(J Bangladesh Coll Phys Surg 2020; 38: 151)

\begin{tabular}{lll}
\hline Serial No. & Name OF Doctors & Date Of Death \\
\hline 1. & Prof Dr Anisur Rahman (M-11) (Forensic Medicine) & $11 / 05 / 2020$ \\
2. & Dr Jafor Hossain Rumie (CMOSGH) & $22 / 05 / 2020$ \\
3. & Dr Tajuddin (MO, DSH) & $28 / 05 / 2020$ \\
4. & Prof. Dr. NI Khan (Medicine) & $04 / 06 / 2020$ \\
5. & Prof Dr Mahbubur Rahman Khan (Surgery) & $03 / 06 / 2020$ \\
6. & DrNurul Haque(CMC-38) (Senior RMO, Chattogram Metropoliton Hospital) & $17 / 06 / 2020$ \\
7. & Dr. Abdul Hye (Ex Civil Surgeon, CoxBazar) & $20 / 06 / 2020$ \\
8. & Dr Shahnewaz (Dental Surgeon) & $21 / 06 / 2020$ \\
9. & Dr Sunil Kumar Sarker (Retd. Cardiac Surgeon, NICVD) & $20 / 06 / 2020$ \\
10. & Dr Shafique Ahmed & $20 / 06 / 2020$ \\
11 & Dr Jannatul Nayem Jinia & $18 / 06 / 2020$ \\
\hline
\end{tabular}

